\title{
Small dense LDL and its Association with Hypertension: a Case-Control Study
}

\author{
S Sharmin'1, MM Hoque ${ }^{2}$, A Ahmed ${ }^{3}$, I Ara ${ }^{4}$, F Afrin ${ }^{5}$, S Islam 6 , S Akhter 7 \\ ${ }^{1}$ Dept of Biochemistry, Holy family Red Cresent Medical College, Dhaka \\ ${ }^{2}$ Dept of Biochemistry, Bangabandhu Sheikh Mujib Medical University, (BSMMU), Dhaka \\ ${ }^{3}$ Dept of Biochemistry National Medical College, Dhaka \\ ${ }^{4}$ Dept of Biochemistry, Popular Medical College, Dhaka \\ ${ }^{5}$ Dept of Biochemistry, Ibn Sina Medical College, Dhaka \\ 6 Anser and VDP Hospital, shafipur, Gazipur \\ ${ }^{7}$ Dept of Biochemistry, National Institute of Neuroscience, Dhaka
}

\section{ABSTRACT}

\begin{abstract}
Hypertension is one of the most common diseases affecting humans throughout the world. The commonest variety of hypertension is benign essential hypertension. Cardiovascular risk is more in hypertensive patients as their lipid profile is more atherogenic than normotensive subjects. Traditionally, estimation of total serum cholesterol and LDL-C are used as an indicator of atherogenicity. But subjects may develop hypertension and CHD with normal levels of LDL cholesterol. So assessment of LDL cholesterol concentration may not entirely reflect its atherogenic potential. Because LDL-C is not a single entity rather it consists of seven distinct subclasses of different particle size. The size of the LDL particle is inversely correlated to their atherogenicity. Smaller LDL particles are more atherogenic despite their less cholesterol content than the larger more buoyant LDL particles containing more cholesterol. Therefore individuals having smaller LDL particles are more atherogenic and more at risk to develop hypertension inspite of even normal LDL cholesterol concentration. So measurement of small dense LDL particle is more important than any other lipid measure. With this aim 122 subjects were included in this study, among them 82 were diagnosed cases of essential hypertension with the mean age of $42.56 \pm 9.98$ years and 40 were healthy controls. Serum apo-B was measured in all study subjects. The amount of apoB is almost similar in every LDL subtypes but the amount of cholesterol increases with the increasing particle size. So the ratio of cholesterol to apo-B decreases as the particle size decreases, thus LDL cholesterol / apo-B $\leq 1$ indicates the presence of atherogenic small dense LDL. So the prevalence of small dense LDL was evaluated by calculating the ratio of LDL-C/apo B. The ratio was significantly lower in hypertensive cases $(0.093 \pm 0.18)$ compared to controls, indicating presence of sd LDL in hypertensive patients. When the risk ratio was calculated, the patients having small dense LDL in their plasma were found to have 2.87 times more risk for developing CVD then the persons who doesn't have small dense LDL in their plasma.
\end{abstract}

Key words: Small dense LDL, Hypertension, apo B, lipid profile

\section{Introduction}

Hypertension is one of the most common diseases affecting humans throughout the world. About 3.45 billion adults in the world are estimated to have hypertension. Untreated hypertension affects all organ system and can shorten one's life expectancy by $10-20$ years ${ }^{1}$.
Despite of its high prevalence and considerable health impact in almost all population, knowledge on risk factors for essential hypertension is still limited ${ }^{2}$. Risk factors for the development of hypertension include positive family history of hypertension, hypercholesterolemia, obesity, sedentary life style, high sodium intake, high dietary fat intake, alcohol use, smoking and stressful lifestyle 3 . 
Elevated low density lipoprotein (LDL) cholesterol concentration has been established as a modifiable risk factor for hypertension. Dyslipidemia, in addition to hypertension may play an important role in initiation and progression of atherosclerosis ${ }^{4}$. Clinical practice has traditionally been based on the concentration of total serum cholesterol total, triglyceride in plasma as well as on LDL cholesterol and HDL cholesterol. Among them, LDL cholesterol has been declared the most important 5 .

LDL is the main carrier of plasma cholesterol and probably the most atherogenic of all lipoproteins and a major component of atherosclerotic plaque 6 .

However, subjects may develop hypertension and CHD with normal levels of LDL cholesterol and assessment of LDL cholesterol concentration may not entirely reflect its atherogenic potential ${ }^{7}$. Because circulating LDL particles differ in size, density, composition and atherogenic potentials 8 .

LDL consists of at least seven distinct subclasses of different particle size ${ }^{7}$. The sizes of the LDL particles are inversely correlated to their atherogenicity. Several lines of evidence indicated that small LDL particle is a risk factor for $\mathrm{CHD}^{7}$. Patients with predominantly small LDL particles are considered to have more atherogenic profile than those with larger particles despite of identical total LDL cholesterol levels ${ }^{9}$. Smaller and denser subtypes are less cholesterol containing but more atherogenic than larger more buoyant particles which are relatively cholesterol rich ${ }^{7}$.

The amount of apoB is almost similar in every LDL subtypes but the amount of cholesterol increases with the increasing particle size. So the ratio of cholesterol to apo-B decreases as the particle size decreases, thus LDL cholesterol/ apoB $\leq 1$ indicates the presence of atherogenic small dense LDL in hypertensive patients 10 .

So to assess accurately the risk from LDL, one needs to know not only the amount of LDL cholesterol but also the number and size of the LDL particles 11 .

LDL particles become smaller and more heterogeneous in hypertensive patients. But this
S Sharmin, MM Hoque, A Ahmed, I Ara, F Afrin

dyslipidemia remain undetected by conventional lipid assay. So subclinical (silent) atherosclerosis develops and patients may present with complications because the total number of LDL particles is more important determinant of risk of vascular disease than any other lipid measures ${ }^{8}$.

Apo-B also significantly increases in hypertensive patients and the ratio of cholesterol to apo-B significantly decreases in LDL and IDL, which indicates the presence of Small dense LDL ${ }^{4}$. Small dense (sd LDL) LDL is the most common profile in patients with hypertension and reduction in small dense LDL may be associated with clinical benefit ${ }^{8}$.

In hypertensive patients, it is more important to find out the presence of sd LDL as their lipid profile is more atherogenic than those of normotensive patients 12 . In our clinical practice conventionally we measure traditional lipid profile to assess the risk in hypertensive patients where we evaluate LDL cholesterol not the LDL particle size or number. Several times we find normal lipid profile in essential hypertension. This is quite expected if an individual contain large number of sd LDL which are cholesterol depleted but highly atherogenic. So normal or even less LDL cholesterol concentration in an individual may in disguise be the harbinger of alarming metabolic and clinical scenario, that we frequently miss looking at the individual through the traditional window of lipid profile.

So assessment of LDL cholesterol concentration may not entirely reflect its atherogenic potential. Assessment of LDL particle size is more comprehensive answer in this situation. So this study has been planned to investigate the LDL subtypes in patients with essential hypertension with normal conventional lipid profile13.

\section{Materials and Methods}

This case-control study was conducted in the department of Biochemistry, Bangabandhu Sheikh Mujib Medical University, Dhaka, Bangladesh during the period from july 2007 to june 2008. In this study our aim was to see the preponderance of sd LDL in essential hypertensive subjects. Hypertension is defined as systolic blood pressure 
Small dense LDL \& its Association with Hypertension

$\geq 140 \mathrm{~mm} \mathrm{Hg}$ and/or diastolic blood pressure $\geq 90 \mathrm{~mm} \mathrm{Hg}$ or current treatment with antihypertensive medication 13 . And essential hypertension means that the underlying cause of hypertension is unknown.

With this aim 82 diagnosed essential hypertensive subjects of both sex and 40 age and sex matched healthy controls were enrolled. All the study subjects were non diabetic and subjects having hepatic failure, renal failure, thyroid disorders were excluded. Patients taking OCP, HRT and lipid lowering drugs were also excluded. On the basis of conventional lipid profile the cases were subdivided into two groups as normolipidaemic and dyslipidaemic. Dyslipidaemia was defined as total cholesterol $>150 \mathrm{mg} / \mathrm{dl}$, triglyceride $>150 \mathrm{mg} / \mathrm{dl}$, LDL cholesterol $>100 \mathrm{mg} / \mathrm{dl} \& \mathrm{HDL}$ cholesterol $<40$ $\mathrm{mg} / \mathrm{dl}$ in men; $50 \mathrm{mg} / \mathrm{dl}$ in women. ApoB was measured in all study subjects. LDL-C/apoB $<1$ indicates presence of atherogenic sd LDL in hypertensive patients. Chi-square test was done to compare sd LDL between and within groups.

\section{Result and Observation}

During the period of july '07 to june '08 a total of 122 subjects of both sexes were selected for the study of which 82 were hypertensive cases and 40 were healthy controls. The mean $( \pm$ SD) age of our cases and controls were $42.56 \pm 9.98$ years and $40.28 \pm 11.80$ years respectively. Among cases 56 were male and 26 were female. And in control group 22 were male and 18 were female.

Table I. Grouping of the study subjects with baseline characteristics

\begin{tabular}{lccc}
\hline Characteristics & $\begin{array}{c}\text { Essential } \\
\text { hypertensive } \\
\text { subjects } \\
\text { Case }(\mathrm{n}=82)\end{array}$ & $\begin{array}{l}\text { Healthy } \\
\text { controls } \\
(\mathrm{n}=40)\end{array}$ & p-value \\
Age & $42.56 \pm 9.98$ & $40.28 \pm 11.88$ & 0.267 \\
\hline Sex male & 56 & 22 & $<0.05$ \\
female & 26 & 18 & 0.481 \\
BMI & $24.91 \pm 1.23$ & $24.43 \pm 1.53$ &
\end{tabular}

p-value reached by unpaired t- test and chi square test.
Table II. Shows small dense LDL status of the cases and controls. $\mathrm{x} 2$ test of association revealed strong association of sd LDL with essential hypertension.

\begin{tabular}{lccc}
\hline Small dense LDL & $\begin{array}{c}\text { Case } \\
(\mathrm{n}=82)\end{array}$ & $\begin{array}{c}\text { Control } \\
(\mathrm{n}=40)\end{array}$ & P value \\
\hline $\begin{array}{l}\text { Predominant } \\
(\mathrm{LDL}-\mathrm{C} / \mathrm{apoB}<1)\end{array}$ & $40(48.8 \%)$ & $10(25 \%)$ & \\
$\begin{array}{l}\text { Not } \\
\text { Predominant } \\
\text { LDL-C/apoB }>1)\end{array}$ & $42(51.2 \%)$ & $30(75 \%)$ & $<0.001$ \\
\hline
\end{tabular}

Table II Small dense LDL status between case \& control Pvalue reached by $\mathrm{x}^{2}$ test.

Table III shows the risk ratio of plasma sd LDL taking serum LDL-C/apoB concentration $<1$ as a cutoff point. Where the ratio $<1$ indicates presence of sd <LDL in plasma. The persons having sd LDL are at 2.87 times more risk for developing cardiovascular events than those having serum apoB/LDL-C $>1$.

Table III Risk ratio of high plasma sd LDL concentration in relation to HTN.

\begin{tabular}{lccc}
\hline Small dense LDL & $\begin{array}{c}\text { Case } \\
(\mathrm{n}=82)\end{array}$ & $\begin{array}{c}\text { Control } \\
(\mathrm{n}=40)\end{array}$ & $\begin{array}{l}\text { Odds } \\
\text { ratio }\end{array}$ \\
\hline $\begin{array}{l}\text { Predominant } \\
(\text { LDL-C/apoB }<1)\end{array}$ & 40 & 10 & \\
$\begin{array}{l}\text { Not } \\
\text { Predominant }\end{array}$ & 42 & 30 & 2.87 \\
LDL-C/apoB $>1)$ & & & \\
\hline
\end{tabular}

\section{Discussion}

In this case-control study our aim was to see the preponderance of small dense LDL in essential hypertensive subjects. With this aim we have measured serum lipid profile and apoB in all the study subjects. Preponderance of small dense LDL was evaluated by LDL-C /apoB ratio.

With respect to lipid profile, hypertensive patients and healthy controls showed significant difference which is in agreement with the findings of other studies $4,12,13,14$.

When LDL-C/apoB ratio was taken into account it was significantly lower in hypertensive cases in comparison to the normotensive controls 
indicating the presence of small dense LDL in hypertensive cases. Many other studies have demonstrated abnormalities in LDL sub fraction profile in patients with uncomplicated essential hypertension. They observed that LDL particles are on average smaller and heterogeneous in hypertensive patients $12,13,14$.

The prevalence of sd LDL was significantly higher in hypertensive cases than normotensive controls. That means small dense LDL is more predominant in hypertensive subjects and it is not independent of traditional lipid profile 15 . But it is an important indicator of plasma atherogenicity in patients with normal traditional lipid profile.

Our present study shows association of sd LDL with essential hypertension. Similar findings were evident in 2 other studies ${ }^{4,12}$.

When the risk ratio was evaluated, the persons having sd LDL in their plasma were at 2.87 times more risk for developing hypertension than those who does not have sd LDL in their plasma.

From this study it can be concluded that sd LDL cholesterol predominate in individuals having essential hypertension. The persons with sd LDL in their plasma are at 2.87 times more risk for developing hypertension when compared with the healthy controls.

\section{References}

1. Abergel, E, Chatellier, G, Battaglia, C. Can echocardiography identify mildly hypertensive patients at high risk, left untreated based on current guidelines? Journal of hypertension 1999; 17: 817-824.

2. Kannel, WB.Risk stratification in hypertension, new insights from the Framingham study. Am J Hypertension 2000; 13: 3s-10s.

3 Landray, MJ, Edmunds E, Li-saw-hee, FL, Hughes, BA, Becvers, DG, Kendall, MJ, Lip, GYH Abnormal low density lipoprotein sub fraction profile in patients with untreated hypertension. Q J Med 2002; 95:165-171.

4. Ryomoto, KI, Suzuki, M, Kanazawa, A, Hasegawa, M, Kimura, Y,Yamamura, T, Harano, Y. Hyperapobetalipoproteinaemia with compositional abnormality of LDL and IDL, a characteristic lipoprotein alteration in essential hypertension. Am J Hypertension 2000; 13: 617-624.
5. Durrington, P \& Sniderman, A. Lipids \& lipoproteinstructure \& physiology, in Durrington P, Sniderman A, Fast Facts hyperlipidaemia, 3rd edn, Health press limited, Oxford. 2005.

6. Steinberg, D, Parsatharathy, S, Carew, T, Khoo, J, Witztum, J.Beyond cholesterol: Modifications of low density lipoprotein that increase its atherogenicity. $\mathrm{N}$ Engl J Med 1989; 320: 915-924.

7. Kullo, IJ, Jan, MF, Bailey, KR, Mosley, TH \& Turner, ST, Ethnic differences in low density lipoprotein particle. J Clin Lipidol 2007; 1: 218-224.

8. Barter, PJ, Ballantyne, CM, Carmena, R, Cabezas, MC, Chapman, MJ,Couture, P,. Apo B versus cholesterol in estimating cardiovascular risk and guiding therapy: report of the thirty-person/ten country panel. J Intern Med 2006; 259: 247-258.

9. Rajman, I, Eacho, PI, Chowienczyk, PJ \& Ritter, JM. LDL Particle size: an important drug target? $\mathrm{Br} \mathrm{J}$ Clin Pharmacol 1999; 48: 125-133.

10. Kral, BG, Becker, LC, Yook, RM, Blumenthal, RS, Kwiterovich, PO, Jr, Otvos, JD, Becker, DM. Racial differences in low density lipoprotein particle size in families at high risk for premature coronary heart disease'. Met Dis 200; 11: 325-337.

11. Castelli, WP, Anderson, $\mathrm{K}$ A population at risk. Prevalence of high cholesterol levels in hypertensive patients in the Framingham study', Am J Med 1986; 80: 23-32.

12. Felmeden, DC, Spencer, CGC, Blann, AD, Becvers, DG, Lip, GYH. Low-density lipoprotein subfractions and cardiovascular risk in hypertension. Relationship to Endothelial Dysfunction and Effects of Treatment. Hypertension 2003; 41: 528-533

13. Ikeda, K, Suzuki, M, Ikebuchi, M, Hara, Y, Tsushima, M, Yamamoto, A, Harano, Y. Hyperbetalipoproteinemia with small density lipoprotein, a characteristic lipoprotein disorder in essential hypertension. J Diabetes Compl cation 1995; 9: 227-229.

14. Rubies-Prat, J, Ordóñez-Llanos, J, Martin, S, BlancoVaca, F, Molina, L, Goday, A, Pedro-Botet, J. Lowdensity lipoprotein particle size, triglyceride-rich lipoproteins, and glucose tolerance in non-diabetic men with essential hypertension. Clin Exp Hypertens 2001; 23(6): 489-500.

15. Koba, S, Hirano, T, Kondo, T, Shibata, M, Suzuki, H, Murakami, MGeshi, E, Katagiri, T. Significance of small dense LDL and other risk factors in various types of coronary heart disease. Am H J 2002; 144 : 1026-1035 